archives

of thermodynamics

Vol. 36(2015), No. 3, 49-59

DOI: 10.1515 /aoter-2015-0021

\title{
Estimation of a tube diameter in a 'church window' condenser based on entropy generation minimization
}

\author{
RAFAŁ LASKOWSKI ${ }^{1}$ \\ ARTUR RUSOWICZ \\ ANDRZEJ GRZEBIELEC
}

Institute of Heat Engineering, Warsaw University of Technology,

Nowowiejska 21/25, 00-665 Warsaw, Poland

\begin{abstract}
The internal diameter of a tube in a 'church window' condenser was estimated using an entropy generation minimization approach. The adopted model took into account the entropy generation due to heat transfer and flow resistance from the cooling-water side. Calculations were performed considering two equations for the flow resistance coefficient for four different roughness values of a condenser tube. Following the analysis, the internal diameter of the tube was obtained in the range of $17.5 \mathrm{~mm}$ to $20 \mathrm{~mm}$ (the current internal diameter of the condenser tube is $22 \mathrm{~mm}$ ). The calculated diameter depends on and is positively related to the roughness assumed in the model.
\end{abstract}

Keywords: Entropy generation minimization; Power plant condenser; Tube diameter

\section{Nomenclature}

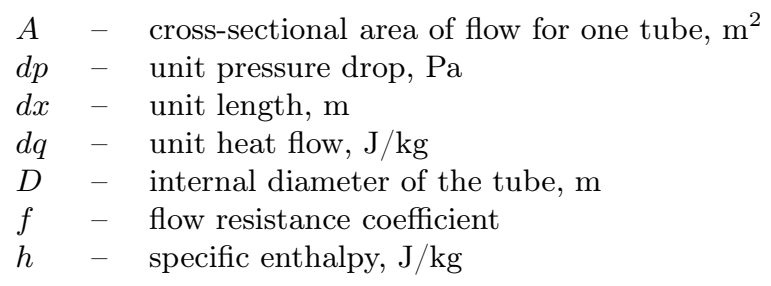

${ }^{1}$ Corresponding Author. E-mail: rlask@itc.pw.edu.pl 


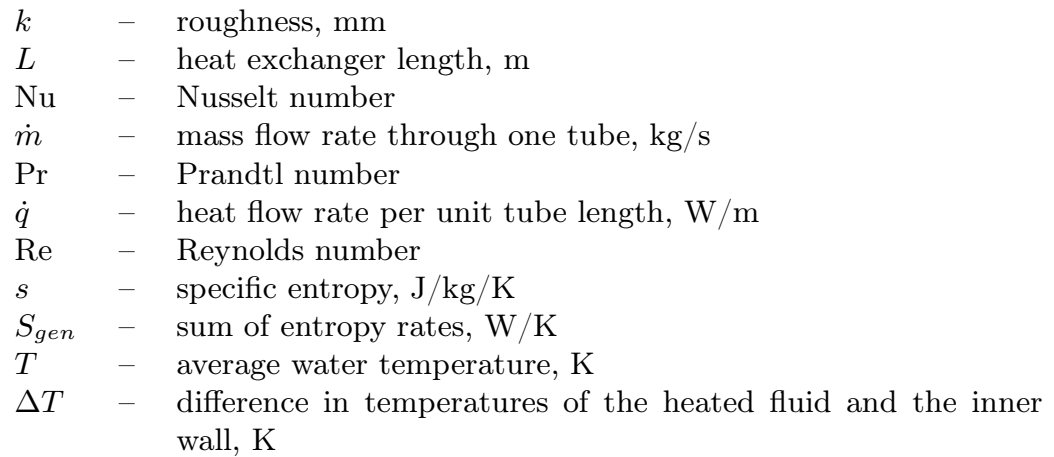

\section{Greek symbols}

$\alpha-$ water heat transfer coefficient, $\mathrm{W} / \mathrm{m}^{2} \mathrm{~K}$

$\lambda-$ thermal conduction coefficient of water, $\mathrm{W} / \mathrm{mK}$

$\mu \quad-$ dynamic viscosity of water, $\mathrm{N} \mathrm{s} / \mathrm{m}^{2}$

$\rho \quad-\quad$ water density, $\mathrm{kg} / \mathrm{m}^{3}$

\section{Introduction}

A condenser is one of key components of the thermal power plant, where it serves as a heat sink (i.e., part of the energy which was not converted into work in a turbine is transferred into the environment). Operating conditions and performance of the condenser affect the efficiency of the whole plant, which is why research has been done for years to improve the condenser efficiency. In steam power units, the condenser is commonly a shell-andtube heat exchanger in which water flows inside a tube bundle; the water is drawn from a lake, river or sea (in a so-called open cooling circuit) or from a tank located under a cooling tower (in a closed cooling circuit). The steam flowing from the turbine condenses on the outer surface of tubes. The condenser effectiveness was mainly improved by providing a special shape of the tube bundle to achieve a good steam flow into each tube in the bundle, and a uniform heat load across all the tubes in the bundle. Following the research, a condenser was developed in the form of a 'church window' tube bundle, named after the shape similar to that of a Gothic window. The church window condenser has one of the most optimal configurations, so the paper focuses on assessing the correct selection of the diameter of the tube in the bundle. For this purpose, the method of entropy generation minimization (EGM) was adopted.

Heat transfer effectiveness is commonly used to assess the heat exchanger performance, defined as the ratio of the actual to the maximum flow rate 
of the heat which can be transferred in the heat exchanger

$$
\varepsilon=\frac{\dot{Q}}{\dot{Q}_{\max }} .
$$

Since the heat transfer effectiveness takes no account of irreversible processes occurring during the heat transfer, the second law of thermodynamics was applied to enable a more comprehensive assessment of the heat exchanger performance. According to the second law of thermodynamics, irreversible processes take place in the heat exchanger during the heat flow, their measure being the rate of entropy generation. The entropy generation rate in the heat exchanger results from the heat flow and the resistance to flow. The heat exchangers should be designed in such a way so that the losses due to irreversible processes accompanying the heat flow are kept as small as possible. McClintock [1] and Prigogine [2] were the first to assess the heat exchanger performance by introducing the EGM method. Based on the EGM, the heat exchanger geometry is commonly determined.

Bejan developed the EGM-based approach and adopted it to various types of heat exchangers [3-5]. EGM was applied to determine heat exchanger geometrical parameters, such as tube diameter, heat exchanger length, and pitch of the tubes [3-11]. Defined parameters have been also proposed on the basis of the entropy generation; e.g., Bejan [3-5] proposed an entropy generation number, $N_{S}$, defined as the entropy generation rate, $S$, divided by the lower heat capacity rate. The parameter proposed by Benjamin, $N_{S}$, was developed in [12-14], and another definition was given under the name of an entropy generation index, equal to the sum of entropy generation rates, $S$, divided by a product of an overall heat transfer coefficient, $U$, and the heat transfer surface area, $A$.

A parameter proposed by Hesselgreaves [15] is equal to the sum of entropy generation rates for the heat exchanger divided by the heat flow rate, allowing for the inlet temperature of the colder fluid so that the proposed parameter is dimensionless (the revised entropy generation number [16]).

Shah and Skiepko [17] presented relations between the entropy generation and heat transfer effectiveness for various types of heat exchangers. They demonstrated that for the minimum entropy generation the effectiveness can have an intermediate maximum or minimum value. Mohammed [18] demonstrated that the heat transfer effectiveness of a heat exchanger should approach one, as in such a case irreversible processes of a smaller extent (lower entropy generation) are expected. He proved that the entropy 
generation associated with the resistance of flow is much lower than that resulting from the heat transfer in the heat exchanger.

In the paper, the internal diameter of tubes in a 'church window' condenser was estimated by applying the EGM method. For this purpose, a model presented in $[4,11,19]$ was adopted. A heat exchanger analysed in these papers had the form of a tube of unknown internal diameter $D$, through which water is flowing at the mass flow rate $\dot{m}$. A constant heat flow rate per tube length unit $\dot{q}$ was provided to the tube. The analysis takes into account the entropy generation resulting from the heat flow and the resistance of flow.

\section{Description of the adopted model}

By analysing a unit tube length, the equation for energy $[4,11,19]$ and entropy balances can be formulated as

$$
\begin{gathered}
\dot{m} d h=\dot{q} d x, \\
d S_{g e n}=\dot{m} d s-\frac{\dot{q} d x}{T+\Delta T} .
\end{gathered}
$$

Enthalpy in the differential form can be expressed as

$$
d h=d q+d p / \rho .
$$

By definition, a unit entropy rate is equal to

$$
d s=\frac{d q}{T} .
$$

A unit flow rate of heat from the wall to water can be written in the form

$$
\dot{q}=\alpha \pi D \Delta T,
$$

where the heat transfer coefficient on the water side is

$$
\alpha=\frac{\mathrm{Nu} D}{\lambda} .
$$

A unit pressure drop on the cooling-water side can be determined from the equation

$$
\frac{d p}{d x}=-\frac{2 f \dot{m}^{2}}{\rho D A^{2}} .
$$


On rearranging Eqs. (2)-(8), we obtain the equation for entropy generation per unit tube length in the form

$$
\frac{S_{g e n}}{L}=\frac{\dot{q}^{2}}{\pi \lambda T^{2} \mathrm{Nu}}+\frac{32 \dot{m}^{3}}{\pi^{2} \rho^{2} T} \frac{f}{D^{5}} .
$$

The assumed Nusselt number for turbulent flow is equal to

$$
\mathrm{Nu}=0.023 \operatorname{Re}^{0.8} \operatorname{Pr}^{0.4} .
$$

The resistance coefficient was determined from two equations. For the first one, the resistance coefficient was only a function of the Reynolds number

$$
f=0.046 \mathrm{Re}^{-0.2} .
$$

For the second one, the flow resistance coefficient was a function of the Reynolds number and roughness according to the Swamee-Jain equation

$$
f=\frac{1}{4} \frac{0.25}{\left[\log \left(\frac{k}{3.7 D}+\frac{5.74}{\operatorname{Re}^{0.9}}\right)\right]^{2}} .
$$

Entropy generation per unit tube length was analysed, considering two equations for the flow resistance coefficient (11) and (12). For Eq. (12) calculations were performed for four values of absolute roughness: $0.01 \mathrm{~mm}$, $0.15 \mathrm{~mm}$, and $0.2 \mathrm{~mm}$.

When Eq. (11) or (12) is considered and the tube internal diameter is expressed as a function of the Reynolds number

$$
D=\frac{4 \dot{m}}{\pi \mu \mathrm{Re}} .
$$

Equation (8) for entropy generation per unit tube length is a function of the Reynolds number, and should attain the minimum value

$$
\frac{S_{g e n}(\mathrm{Re})}{L} \rightarrow \min .
$$

\section{Description of the condenser under consideration}

The model was used to estimate the internal diameter of a tube in a 'church window' condenser. Condensers of this type are divided into modules with 
wide channels between the modules, facilitating the steam flow to a whole bundle also from the bottom. In recent designs, a non-uniform pitch of tubes in the bundle was introduced to minimize the resistance to steam flow; in the outer part the tubes are located farther from each other than in the internal one $[21,22]$. Thanks to the modular design of the condenser, another tube bundle can be added, depending on the power unit output; hence, this design can be found in power units with power ranging from 200 to 1200 MWe [21,22]. A diagram of the condenser under consideration is show in Fig. 1. Basic geometrical data and operating parameters of the condenser in question are listed in Tab. 1.

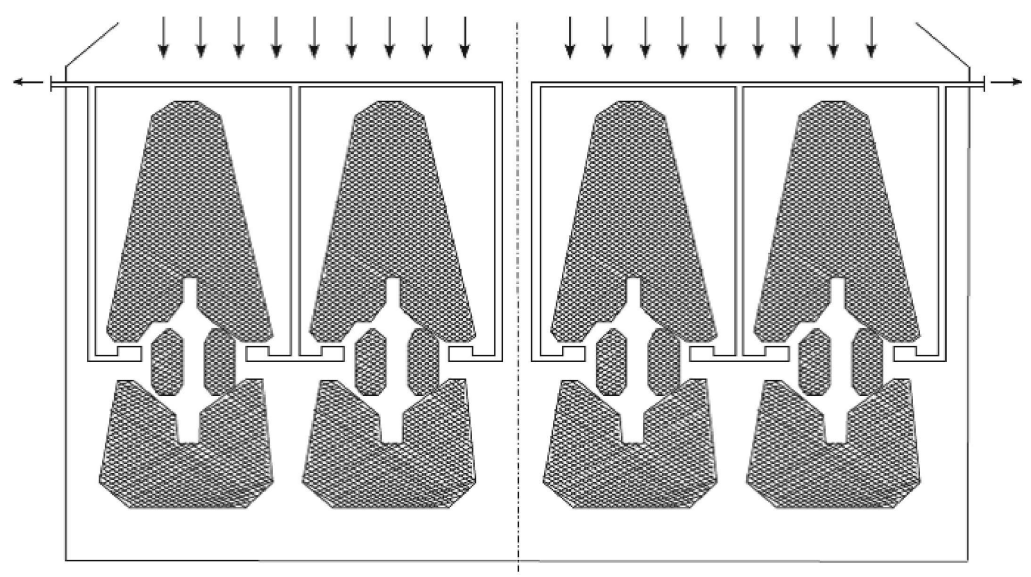

Figure 1: A diagram of the 'church window' condenser under consideration [22].

\section{Results}

Figure 2 shows a total change in the entropy generation per unit tube length as a function of the Reynolds number, considering two equations for the flow resistance according to Eqs. (11) and (12), and four roughness values. For all the patterns analysed, a minimum entropy generation exists, and its value depends on the assumed roughness. For the least roughness, equal to $0.01 \mathrm{~mm}$, the minimum is reached for the Reynolds number of 61913 . For the largest roughness, equal to $0.2 \mathrm{~mm}$, the minimum is reached for the Reynolds number of 55403 . The larger roughness is assumed, the smaller is the Reynolds number for which the minimum entropy generation occurs. 
Table 1: Basic data of the condenser concerned.

\begin{tabular}{|l|c|}
\hline \multicolumn{2}{|c|}{ Geometrical data } \\
\hline \hline Number of tubes & 3220 \\
\hline Heat exchanger length $[\mathrm{m}]$ & 9.94 \\
\hline Tube external diameter [mm] & 24 \\
\hline Tube internal diameter [mm] & 22 \\
\hline Pitch [mm] Operating parameters & 32 \\
\hline Tube material & Brass \\
\hline \multicolumn{2}{|c|}{} \\
\hline \hline Cooling water temperature at the heat exchanger inlet $\left[{ }^{\circ} \mathrm{C}\right]$ & 22.4 \\
\hline Average cooling water speed in tubes $[\mathrm{m} / \mathrm{s}]$ & 2.0 \\
\hline Condensing steam mass flow rate $[\mathrm{kg} / \mathrm{s}]$ & 49.36 \\
\hline
\end{tabular}

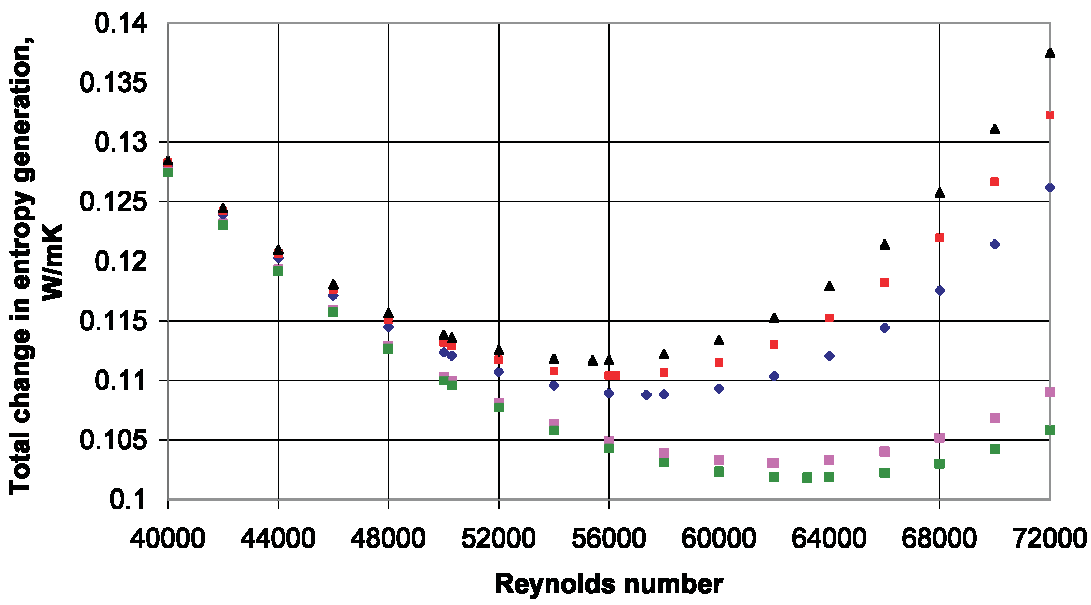

- $0.1 \mathrm{~mm}=0.15 \mathrm{~mm} \triangle 0.2 \mathrm{~mm}=0.01 \mathrm{~mm}=$ Eq. $(11)$

Figure 2: Total change in entropy generation per unit tube length in a 'church window' condenser as a function of the Reynolds number, with roughness included.

Figure 3 shows a total change in the entropy generation per unit tube length as a function of the internal diameter of the tube, $D$, considering two equations for the flow resistance, according to Eqs. (11) and (12), and four roughness values. An increase in the assumed roughness increases the value of the internal diameter of the condenser tube for which the minimum 


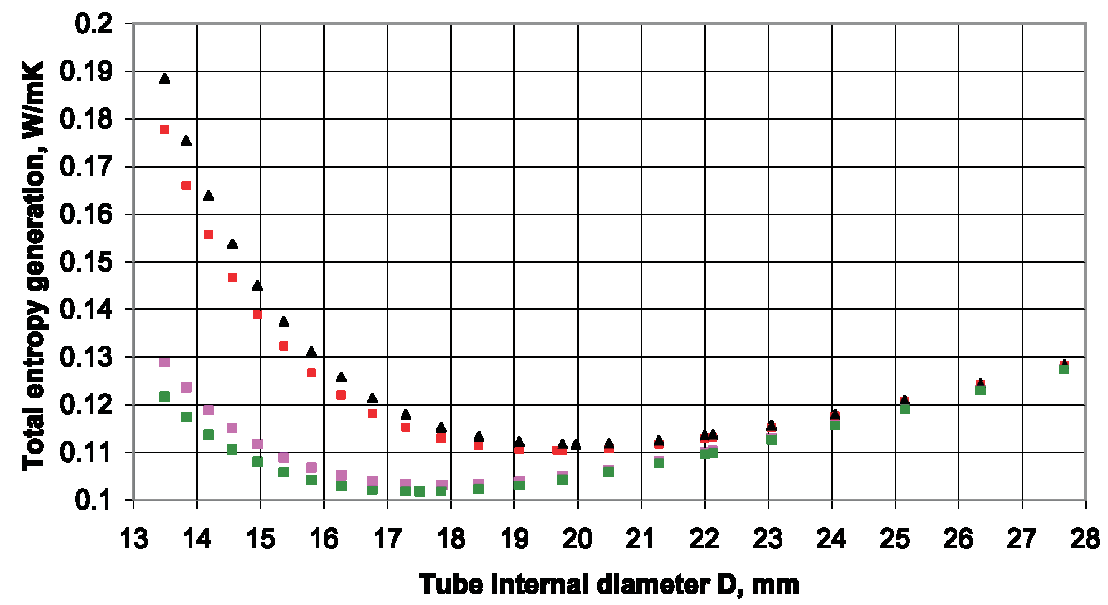

$\cdot 0.1 \mathrm{~mm}=0.15 \mathrm{~mm} \triangle 0.2 \mathrm{~mm}=0.01 \mathrm{~mm}=\mathrm{Eq} .(11)$

Figure 3: Total change in entropy generation per unit tube length in a 'church window' condenser as a function of the internal diameter of the tube, with roughness included.

entropy generation occurs. For roughness equal to $0.01 \mathrm{~mm}$, the minimum entropy generation is reached when the internal diameter of the tube is $17.9 \mathrm{~mm}$, while for the roughness of $0.2 \mathrm{~mm}$, the minimum entropy generation is reached when the internal diameter of the tube is $20 \mathrm{~mm}$.

Quantities for the minimum entropy generation, i.e., tube internal diameter, Nusselt number, coefficient of heat transfer from the water side, heat transfer surface area, average water speed in the tubes, pressure drop, and Reynolds number, are listed in Tab. 2.

Table 2: Parameters for the minimum entropy generation in a 'church window' condenser.

\begin{tabular}{|c|c|c|c|c|c|c|c|c|}
\hline Roughness & $\mathrm{D}$ & $S_{\text {gen }}$ & $\mathrm{Nu}$ & $\alpha_{2}$ & $\mathrm{~A}$ & $\mathrm{w}$ & $\mathrm{dp}$ & Reynolds number \\
\hline $\mathrm{mm}$ & $\mathrm{mm}$ & $\mathrm{W} / \mathrm{mK}$ & - & $\mathrm{W} / \mathrm{m}^{2} \mathrm{~K}$ & $\mathrm{~m}^{2}$ & $\mathrm{~m} / \mathrm{s}$ & $\mathrm{kPa}$ & - \\
\hline \hline $\mathrm{f}$ & 17.5 & 0.1018 & 326 & 11336 & 1761 & 3.16 & 5.69 & 63193 \\
\hline 0.01 & 17.9 & 0.1031 & 321 & 10927 & 1797 & 3.03 & 56.2 & 61913 \\
\hline 0.10 & 19.3 & 0.1088 & 302 & 9523 & 1940 & 2.60 & 56.6 & 57360 \\
\hline 0.15 & 19.7 & 0.1104 & 297 & 9191 & 1978 & 2.50 & 57.1 & 56242 \\
\hline 0.20 & 20.0 & 0.1117 & 293 & 8946 & 2008 & 2.43 & 57.5 & 55403 \\
\hline
\end{tabular}




\section{Conclusions}

'Church window' condensers are among more recent designs used to condense steam in conventional steam power units and have one of the most optimum tube bundle configuration. The paper presents a estimation of a tube diameter in this type of condenser based on the entropy generation minimization. The analysis takes into account the entropy generation resulting from the heat flow and the resistance to flow from the water side. For the minimum value of the total entropy generation, the value of the Reynolds number and the corresponding internal diameter of the tube were determined.

The analysis was performed for two equations for the flow resistance according to Eqs. (11) and (12), and four roughness values. For the largest assumed tube roughness of $0.2 \mathrm{~mm}$, the obtained internal diameter of the tube was $20 \mathrm{~mm}$ (the current tube internal diameter is $22 \mathrm{~mm}$ ). The diameter depends on and is positively related to the assumed roughness. The results of the analysis lead to a conclusion that decreasing the internal diameter of the tube by about $2 \mathrm{~mm}$ could be considered. If the tube diameter is decreased while the same flow rate of water through the tube is kept, the average water speed in the tubes will increase by $0.4 \mathrm{~m} / \mathrm{s}$, which will lead to improving heat transfer conditions, and increasing the Nusselt number and the heat transfer coefficient. Additionally, with decreased internal diameter and the same number of tubes, the heat transfer surface area is smaller, and so is the cost of building the heat exchanger. The increase in the average water speed in the tubes increases the flow resistance. The advantages (larger heat transfer coefficient, smaller heat transfer surface area, lower cost of building the heat exchanger) of decreasing the internal diameter of the tube by about $2 \mathrm{~mm}$ seem to prevail over this negative effect (larger flow resistance).

The diameter of the condenser tubes can also be determined based on the condenser performance in a thermal system of a power unit. This requires a comprehensive heat and flow analysis taking into account the change in the cost of the condenser.

The method presented in the paper allows to obtain a satisfactory assessment of the diameter of condenser tubes without the need to perform such a complex feasibility study. 


\section{References}

[1] McClintock F. A.: The design of heat exchangers for minimum irreversibility. ASME Paper 51-A-108, 1951.

[2] Prigogine I.: Introduction to Thermodynamics of Irreversible Processes, 3rd Edn., Wiley, New York 1967, 76-77.

[3] Bejan A.: The concept of irreversibility in heat exchanger design: counter flow heat exchanger for gas-gas applications. J. Heat Transfer 99(1977), 374-380.

[4] BejAn A.: Entropy generation minimization: The new thermodynamics of finite size devices and finite time processes. J. Appl. Phys. 79(1996), 1191-1218.

[5] BeJAn A.: Entropy Generation Minimization: The Method of Thermodynamic Optimization of Finite-Size Systems and Finite-Time Processes. CRC Press LLC, 1996.

[6] Ordonez J., Bejan A.: Entropy generation minimization in parallel-plates counterfow heat exchangers. Int. J. Energ. Res. 24(2000), 843-864.

[7] Ogulata R.T., Doba F., Yilmaz T.: Irreversibility analysis of cross flow heat exchangers. Energ. Convers. Manage. 41(2000), 1585-1599.

[8] Sahiti N., Krasniqi F., Fejzullahu Xh., Bunjaku J., Muriqi A.: Entropy generation minimization of a double-pipe pin fin heat exchange. Appl. Therm. Eng. 28(2008), 2337-2344.

[9] Mishra M., Das P.K., Sarangi S.: Second law based optimisation of crossflow plate-fin heat exchanger design using genetic algorithm. Appl. Therm. Eng. 29(2009) 2983-2989.

[10] Guo, J., Cheng, L., Xu, M.: Multi-Objective Optimization of Heat Exchanger Design by Entropy Generation Minimization. J. Heat Trans.-T. ASME 132(2010), $8,081801$.

[11] Szargut J.: Problems of thermodynamics optimization. Arch. Thermodyn. 19(1998), 3/4, 85-94.

[12] OGISO K.: Duality of heat exchanger performance in balanced counter-flow systems. J. Heat Trans.-T. ASME 125(2003), 3, 530-532.

[13] Xu Z., Yang S., Chen Z.: A modified entropy generation number for heat exchangers. J. Therm. Sci. 5(1996), 4, 257-263.

[14] Xiong Daxi Li Zhixin Guo Zengyuan: On effectiveness and entropy generation in heat exchange. J. Therm. Sci. 5(1996), 4.

[15] Hesselgreaves J.E.: Rationalization of second law analysis of heat exchangers. Int. J. Heat Mass Tran. 43(2000, 4189-4204.

[16] Guo J., Xu M., Cheng L.: The application of field synergy number in shell-andtube heat exchanger optimization design. Appl. Energ. 86(2009), 2079-2087.

[17] Sнан R.K., Sкiepko T.: Entropy generation extrema and their relationship with heat exchanger effectiveness-number of transfer unit behavior for complex flow arrangements. J. Heat Trans.-T. ASME 126(2004), 6, 994-1002.

[18] Mohamed H.A.: Entropy generation in counter flow heat exchangers. J. Heat Trans.-T. ASME 128(2006), 87-92. 
[19] Kolenda Z.: Analysis of the possibility to reduce the imperfections of the thermodynamic processes of the supply of electricity, heat and cooling in the context of sustainable development of the country. Exergy analysis and entropy generation minimization method. (A. Ziębik, J. Szargut, W. Stanek, Eds.). Wyd. PAN, 2006 (in Polish).

[20] Yilmaz M., Sara O. N., Karsli S.: Performance evaluation criteria for heat exchangers based on second law analysis. Exergy Int. J. 1(2001), 4, 278-294.

[21] Zeng H., Meng J., Li Z.: Numerical study of a power plant condenser tube arrangement. Appl. Therm. Eng. 40(2012), 294-303.

[22] Rusowicz A.: Issues concerning mathematical modeling of power condensers. Warsaw University of Technology, Warsaw 2013 (in Polish). 